Profesionalisme guru pendidikan jasmani: dari kepemimpinan kepala sekolah, budaya sekolah hingga motivasi kerja guru

\title{
Professionalism of physical education teachers: From the leadership of school principals, school culture to teacher work motivation
}

\author{
Albadi Sinulingga ${ }^{1}$, Suprayitno ${ }^{2}$, dan Dian Pertiwi ${ }^{3}$ \\ ${ }^{1,2,3}$ Department of Sport Education, Universitas Negeri Medan, Jl. Willem Iskandar \\ No.14B, Medan, Sumatera Utara, 20221, Indonesia
}

Received: 2 July 2019; Revised: 10 October 2019; Accepted: 18 October 2019

doi https://doi.org/10.29407/js unpgri.v5i2.13113

\begin{abstract}
Abstrak
Penelitian ini bertujuan untuk memperoleh gambaran tentang hubungan antara kepemimpinan kepala sekolah, budaya sekolah dan motivasi kerja guru terhadap profesionalisme guru Pendidikan Jasmani. Penelitian menggunakan pendekatan kuantitatif dengan metode Ext-Post Facto. Populasi dalam penelitian ini berjumlah 952 orang dari 34 Sekolah Menengah Kejuruan (SMK) Negeri dan Swasta yang terdaftar didalam data MGMP (Musyawarah Guru Mata Pelajaran) Pendidikan Jasmani SMK Kabupaten Serdang Bedagai di Provinsi Sumatera Utara tahun 2017. Sampel sebanyak 30 guru pendidikan jasmani dari 34 Sekolah dengan menggunakan teknik purposive sampling. Teknik pengambilan data menggunakan angket. Teknik analisis data menggunakan analysis path. Hasil penelitian menunjukkan bahwa kepemimpinan kepala sekolah dan motivasi kerja guru berpengaruh secara langsung terhadap profesionalisme guru, sedangkan budaya sekolah tidak akan mempengaruhi profesionalisme guru. Kesimpulannya bahwa kepemimpinan kepala sekolah yang baik, budaya sekolah yang sehat, dan motivasi kerja guru yang tinggi merupakan faktor tinggi rendahnya profesionalisme guru.
\end{abstract}

Kata kunci: profesionalisme guru, kepemimpinan kepala sekolah, budaya sekolah, motivasi kerja, pendidikan jasmani.

\begin{abstract}
This study aims to obtain an overview of the relationship between school principal leadership, school culture and teacher work motivation on the professionalism of physical education teachers. The study uses a quantitative approach with the Ext-Post Facto method. The population in this study amounted to 952 people from 34 Public and Private Vocational High Schools (SMK) registered in MGMP (Subject Teachers' Consultation) Physical Education Vocational School Physical Education Serdang Bedagai Regency in North Sumatra Province in 2017. Samples of 30 physical education teachers from 34 Schools using purposive sampling techniques. Data collection techniques using a questionnaire. Data analysis techniques using path analysis. The results showed that the principal's leadership and work motivation of teachers directly affected teacher professionalism, while school culture would not affect teacher professionalism. The conclusion is that the principal's good leadership, healthy school culture, and high teacher motivation are factors of high and low teacher professionalism.

Keyword: teacher professionalism, headmaster leadership, school culture, work motivation, physical education.
\end{abstract}


Albadi Sinulingga, Suprayitno, dan Dian Pertiwi

Profesionalisme guru pendidikan jasmani: dari kepemimpinan kepala sekolah, budaya sekolah hingga motivasi kerja guru

\section{PENDAHULUAN}

Dinamika perkembangan dunia pendidikan ditandai dengan munculnya Undang-Undang No 14 Tahun 2005 tentang Guru dan Dosen bahwa pembangunan nasional ditujukan untuk meningkatkan kualitas manusia di seluruh Indonesia (Hoesein, 2015). Pendidikan memainkan peran penting dalam membentuk masyarakat dan pembangunan bangsa (Husain, Hasan, Wahab, \& Jantan, 2015). Semua usaha pembangunan nasional dalam bidang pendidikan bertumpu pada Guru dan Dosen, khususnya Guru yang memiliki peran strategis pada pendidikan wajib belajar 12 tahun menjadi perhatian bagi peneliti. Keberhasilan pendidikan tidak terlepas dari peran Guru (Bank Dunia, 2011; Harmono, 2017; Muhson, 2012). Meskipun juga ditentukan oleh faktor lain seperti kurikulum, prasarana dan sarana, lingkungan, manajemen pendidikan, dan bakat dari siswa (Jakaria, 2014), maka dari itu, sudah sepantasnya Guru senantiasa untuk terus mengembangkan dan meningkatkan kompetensinya (Muhson, 2012).

Menurut Husain et al. (2015) guru yang baik dan berkualitas adalah salah satu faktor yang mempengaruhi belajar siswa dibandingkan dengan faktor lain. Husain et al. (2015) juga menyatakan bahwa seorang guru yang sangat bersemangat dalam mengajar, memiliki disiplin yang tinggi dan mengikuti pelatihan pengajaran profesional akan dapat menarik minat siswa dalam belajar. Dalam rangka mencapai Guru yang professional, Guru dituntut untuk memiliki empat kompetensi, yakni kompetensi pedagogik, kompetensi kepribadian, kompetensi sosial dan kompetensi profesional (Supriadi, 2009). Keempat kompetensi tersebut harus dimiliki guru dalam bidang pendidikan.

Data Direktorat Tenaga Kependidikan Dikdasmen pada tahun 2004 menunjukkan terdapat 991.243 (45,96\%) dari guru SD, SMP, SMA dan SMK tidak memenuhi kualifikasi pendidikan minimal. Secara kualifikasi dan kompetensi dari sekitar 2,191 juta guru SD dan SMP, 67\% telah berkualifikasi sarjana $S 1$ ke atas, namun sekitar $43 \%$ yang bersertifikat pendidik masih terdapat sekitar 57\%-nya atau sekitar 12 juta guru belum 
memiliki sertifikat mengajar (Samto, 2014). Data Balitbang Depdiknas (sekarang Kemendiknas), hingga tahun 2007/2008 menyatakan bahwa masih banyak guru SMK yang belum berijasah S1 (23,04\%) dan sebesar 23,04\% guru SMK tidak layak mengajar pada tahun 2007/2008 (Mahdiansyah, 2010). Polemik ini lah yang menengarai rendahnya mutu pendidikan di Indonesia. Meskipun pada tahun 2005 pemerintah telah mengeluarkan Undang-Undang No 14 tentang Guru dan Dosen namun hal itu tidak serta merta dapat meningkatkan profesionalisme guru.

Pada tahun 2012 hasil UKG nasional mendapat nilai rata-rata 53.05. Sedangkan pada tahun 2015 menurun dengan nilai rata-rata 42.25. Hasil tersebut jauh dari harapan pemerintah yang menetapkan rata-rata nasional untuk nilai UKG sebesar 55.00. Dengan kata lain, melihat hasil UKG di atas guru-guru yang ada di Indonesia memiliki kompetensi yang masih dibawah rata-rata. Di Sumatera Utara sendiri, hasil nilai UKG tahun 2012 yaitu mencapai nilai rata-rata 48.96, sedangkan tahun 2015 hanya mendapat nilai 37.40 .

Dari data UKG tahun 2015 diperoleh dari Dinas Pendidikan bahwa rata-rata nilai yang didapat guru Pendidikan Jasmani tingkat Sekolah Menengah Kejuruan di Kabupaten Serdang Bedagai adalah 52.27. Disini terlihat nilai yang diperoleh tidak dapat mencapai nilai rata-rata yang telah ditentukan oleh pemerintah yakni 55.00. Hal ini membuktikan bahwa profesionalisme guru Pendidikan Jasmani tingkat SMK di Kabupaten Serdang Bedagai masih rendah. Walaupun demikian UKG bukanlah satusatunya patokan yang menyatakan rendahnya profesionalisme guru di Kabupaten Serdang Bedagai. Namun demikian dengan nilai yang didapat dari proses UKG ini guru mengetahui sejauh mana kemampuan profesional seorang guru karena dalam UKG ada dua faktor yang di ujikan yaitu kompetensi profesional dan kompetensi paedagogik.

Konsep profesionalisme dalam pengajaran umumnya dibahas pada dasar sosiologis, pendidikan dan ideologis dalam literature (Demirkasimoğlu, 2010). Profesionalisme guru didefinisikan sebagai tanggung jawab guru untuk mengendalikan dan mengembangkan 
pengetahuan dan tindakan mereka sendiri untuk kepentingan klien (Saqipi, Asunta, \& Korpinen, 2014).

Nuraeni (2015) menyatakan bahwa "profesionalisme guru dipengaruhi oleh dua faktor, yaitu faktor internal yang meliputi minat dan bakat serta faktor eksternal yang berkaitan dengan lingkungan sekitar (termasuk kebijakan), sarana-prasarana, dan pelatihan yang diikuti". Faktor internal adalah faktor yang ada dalam diri seorang guru diantaranya motivasi, bakat, minat dan panggilan jiwa. Seperti yang di jelaskan oleh Abast (2011) dalam penelitiannya bahwa secara teoritis seorang guru akan memiliki produktivitas kerja yang baik jika ada motivasi kerja. Dengan adanya motivasi kerja yang tinggi dapat memacu semangat untuk terus meningkatkan profesionalisme guru.

Menurut Astuti (2015) seorang guru dikatakan profesional apabila memiliki kemampuan tinggi (high level of abstract) dan motivasi kerja tinggi (high level of commitment). Seorang guru yang memiliki motivasi kerja tinggi akan memiliki kemauan yang keras atau kesungguhan hati untuk mengerjakan tugas-tugasnya (Setiyati, 2014), sehingga profesionalisme akan terus meningkat. Sebaliknya seorang guru yang memiliki motivasi kerja yang rendah tidak akan memiliki kemauan yang keras untuk mengerjakan tugas yang diberikan, sehingga berakibat profesionalisme guru menurun. Dengan demikian penting untuk menumbuhkan motivasi diri pada setiap guru untuk menciptakan guru yang profesional dibidang masing-masing yang nanti akan meningkatkan mutu pendidikan di Indonesia.

Guru dapat meningkatkan profesionalisme mereka melalui kegiatan formal dan informal. Menurut Mizzel (2010), pengembangan profesional dapat dilakukan melalui proses formal seperti konferensi, seminar, atau lokakarya dan juga dapat terjadi dalam konteks informal seperti diskusi di antara rekan kerja, bacaan dan penelitian independen, pengamatan karya rekan kerja, atau pembelajaran lain dari teman sebaya.

Peran kepemimpinan kepala sekolah sangat penting untuk meningkakan mutu pendidikan dan memotivasi guru untuk dapat 
mengembangkan kompetensi yang dimilki demi tercipta guru profesional. Sejalan dengan itu Emmanouil, Osia, \& Paraskevi (2014) mengemukakan bahwa "Effective leadership has a key role in motivating teachers towards individual and shared learning, a factor which is considered to be quite important for school effectiveness to be achieved". Artinya bahwa kepemimpinan yang efektif adalah kunci di dalam memotivasi guru terhadap pembelajaran individual dan pembelajaran bersama, faktor yang dianggap cukup penting untuk efektivitas sekolah yang ingin dicapai. Sehingga untuk membentuk guru yang profesional dilatar belakangi oleh beberapa faktor seperti yang telah diuraikan di atas yaitu kepemimpinan kepala sekolah, budaya organisasi (sekolah), dan motivasi kerja guru.

Budaya sekolah juga menjadi faktor eksternal lain dalam meningkatkan profesionalisme guru, hal ini didukung oleh Zubaidah (2015) bahwa,"budaya sekolah merupakan jiwa (spirit) sebuah sekolah yang memberikan makna terhadap kegiatan pendidikan sekolah tersebut, jika budaya sekolah lemah, maka tidak kondusif bagi pembentukan sekolah efektif". Budaya sekolah terbentuk atas dasar penerimaan secara bersama tentang sistem nilai, kepercayaan dan norma dan dilaksanakan dengan penuh tanggun jawab (Setiyati, 2014).

Selain dari pada itu Maister dalam Nuraeni (2015) juga menyatakan "bahwa profesionalisme bukan sekedar pengetahuan teknologi dan manajemen tetapi lebih merupakan sikap, dengan pengembangan profesionalisme diharapkan guru tidak hanya memiliki keterampilan yang tinggi tetapi juga tingkah laku yang dipersyaratkan". Sikap dan tingkah laku di atas mengarah kepada budaya sekolah, dimana budaya sekolah yang baik akan menghasilkan perilaku dan sikap yang baik pula pada setiap warga sekolahnya begitu pula sebaliknya apabila budaya sekolah tidak sehat maka cenderung akan mengarah kepada perilaku dan sikap yang negatif pada bawahan.

Pendidikan jasmani merupakan proses belajar bergerak, Hanief \& Sugito (2015) menjelaskan bahwa pendidikan jasmani merupakan proses belajar untuk bergerak dan belajar melalui gerak. Maksudnya adalah 
melalui pendidikan jasmani peserta didik mampu belajar gerak dengan benar dan melalui gerak pula peaserta didik mendapat pembelajaran. Bukan hanya sebatas bergerak, namun pendidikan jasmani mengajarkan bergerak dan berkembang. Suharjo (2015) juga menjelaskan bahwa perkembangan yang dimaksud bersifat menyeluruh sebab yang dituju bukan hanya aspek jasmaniah yang lazim dicakup dalam istilah psikomotorik, namun juga perkembangan pengetahuan dan penalaran yaitu kemampuan kognitif dan watak serta sifat-sifat kepribadian yang disebut afektif.

Guru pendidikan jasmani harus memiliki kompetensi yang memenuhi standar agar dapat memahami kemampuan serta bakat yang dimiliki setiap peserta didik. Dalam pelaksanaannya proses pembelajaran pendidikan jasmani belum sesuai seperti yang diharapkan. Suharjo (2015) menjelasakan bahwa, "kondisi seperti ini dipengaruhi oleh beberapa faktor yaitu terbatasnya kemampuan guru pendidikan jasmani dan terbatasnya sumber-sumber yang digunakan untuk mendukung proses pengajaran pendidikan jasmani". Guru pendidikan jasmani yang memiliki kemampuan yang profesional diharapkan akan mampu menggali potensi peserta didik dan dapat mengarahkan bakat tersebut agar dapat berkembang dengan baik.

Beberapa penelitian terkait kepemimpinan kepala sekolah, budaya sekolah dan motivasi kerja guru telah menunjukkan pengaruhnya terhadap kinerja guru. Rini (2018) menyimpulkan bahwa kepemimpinan kepala sekolah, budaya sekolah dan iklim sekolah berpengaruh terhadap kompetensi kepribadian guru. Setiyati (2014) menyimpulkan kepemimpinan kepala sekolah, motivasi kerja, dan budaya sekolah berpengaruh terhadap kinerja guru. Manik \& Bustomi (2011) menyimpulkan bahwa kepemimpinan kepala sekolah, budaya organisasi, dan motivasi kerja berpengaruh terhadap kinerja guru. Ketiga penelitian tersebut menunjukkan bahwa kepemimpinan kepala sekolah, budaya sekolah, dan motivasi kerja berpengaruh terhadap kinerja guru. Namun, Syakir \& Pardjono (2015) menyimpulkan bahwa kepemimpinan kepala 
sekolah dan motivasi kerja tidak berpengaruh terhadap kompetensi guru SMA. Peneliti ingin menguji secara empiris dari variabel kepemimpinan kepala sekolah, budaya sekolah, dan motivasi kerja terhadap profesionalisme guru, karena terjadi kontradiksi antar hasil temuan.

\section{METODE}

Penelitian ini merupakan penelitian kuantitatif dengan metode ex post facto untuk mengetahui peristiwa-peristiwa yang telah lalu guna mengungkap data untuk menjari jawaban atas permasalahan yang ingin diungkap dengan menggunakan sistem analisis jalur atau dalam statistik disebut dengan path analysis. Teknik pengambilan data dilakukan melalui survey penelitian dengan menggunakan teknik angket. Populasi dalam penelitian ini berjumlah 952 orang dari 34 Sekolah Menengah Kejuruan (SMK) Negeri dan Swasta yang terdaftar didalam data MGMP (Musyawarah Guru Mata Pelajaran) Pendidikan Jasmani SMK Kabupaten Serdang Bedagai di Provinsi Sumatera Utara tahun 2017. Peneliti mengambil sample sebanyak 30 guru Pendidikan jasmani dari 34 Sekolah dengan menggunakan teknik Purposive Sampling, karena peneliti memiliki pertimbangan tertentu yang sudah diketahui sebelumnya.

\section{HASIL DAN PEMBAHASAN}

\section{Hasil}

Dengan menggunakan instrumen penelitian maka diperoleh data Kepemimpinan Kepala Sekolah $\left(\mathrm{X}_{1}\right)$, Budaya Sekolah $\left(\mathrm{X}_{2}\right)$, Motivasi Kerja Guru $\left(\mathrm{X}_{3}\right)$, dan Profesionalisme Guru (Y) yang telah di uji validitas dan realibilitasnya terlebih dahulu.

Tabel 1. Ringkasan hasil penelitian dari setiap variabel

\begin{tabular}{lllll}
\hline Nilai Statistik & $\mathrm{Y}$ & $\mathrm{X}_{1}$ & $\mathrm{X}_{2}$ & $\mathrm{X}_{3}$ \\
\hline Skore tertinggi & 201 & 145 & 82 & 97 \\
\hline Skore terendah & 115 & 70 & 54 & 58 \\
\hline Modus & 170,5 & 122,25 & 74,25 & 74,25 \\
\hline Median & 170,83 & 102,722 & 67,278 & 80,056 \\
\hline Rerata & 158,53 & 103,733 & 67,167 & 75,467 \\
\hline Simpangan & 27,414 & 22,05 & 9,25 & 11,616 \\
\hline Rata-rata Ideal & 123 & 93 & 57 & 63 \\
\hline Simpangan baku Ideal & 27 & 21 & 19 & 14 \\
\hline Sumber: Pengolahan Data & & & & \\
\hline
\end{tabular}


Profesionalisme guru pendidikan jasmani: dari kepemimpinan kepala sekolah, budaya sekolah hingga motivasi kerja guru

\section{a. Profesionalisme Guru}

Dapat diketahui bahwa skor rata-rata kelas Profesionalisme Guru yaitu 157,9 dan berada di kelas interval (157-170). Dengan demikian, sebanyak 13 guru PJOK (43\%) berada di bawah skor rata-rata, 6 orang guru PJOK (20\%) berada pada skor rata-rata, dan 11 orang guru PJOK (37\%) berada pada skor di atas rata-rata. Berikut adalah gambar Histogram distribusi skor variabel Profesionalisme Guru PJOK.

\section{b. Kepemimpinan Kepala Sekolah}

Dapat diketahui bahwa skor rata-rata kelas Kepemimpinan Kepala Sekolah yaitu 103,7 dan berada di kelas interval (96-108). Dengan demikian, sebanyak 10 guru PJOK (33\%) berada di bawah skor rata-rata, 9 orang guru PJOK (30\%) berada pada skor rata-rata, dan 11 orang guru PJOK (37\%) berada pada skor di atas rata-rata. Berikut ini adalah gambar histogram distribusi skor variabel Profesionalisme Guru PJOK.

\section{c. Budaya Sekolah}

Dapat diketahui bahwa skor rata-rata kelas Budaya Sekolah yaitu 67,16 dan berada di kelas interval (64-68). Dengan demikian, sebanyak 14 guru PJOK (47\%) berada di bawah skor rata-rata, 2 orang guru PJOK (6\%) berada pada skor rata-rata, dan 14 orang guru PJOK (47\%) berada pada skor di atas rata-rata. Berikut ini adalah gambar histogram distribusi skor variabel Profesionalisme Guru PJOK.

\section{d. Motivasi Kerja Guru}

Dapat diketahui bahwa skor rata-rata kelas Motivasi Kerja Guru yaitu 75,46 dan berada di kelas interval (72-78). Dengan demikian, sebanyak 14 guru PJOK (47\%) berada di bawah skor rata-rata, 4 orang guru PJOK (13\%) berada pada skor rata-rata, dan 12 orang guru PJOK (40\%) berada pada skor di atas rata-rata. Berikut ini adalah gambar histogram distribusi skor variabel Profesionalisme Guru PJOK.

Analisis korelasi bertujuan untuk mengetahui arah dan kekuatan hubungan antara dua variabel atau lebih. Dari perhitungan SPSS diperoleh korelasi antar variabel adalah sebagai berikut: 
1. Hubungan antara Kepemimpinan Kepala Sekolah (X1) terhadap Motivasi Kerja Guru (X3) adalah 0, 715. Nilai ini masuk kedalam kategori kuat.

2. Hubungan antara Budaya Sekolah (X2) terhadap Motivasi Kerja Guru (X3) adalah 0, 505. Nilai ini masuk kedalam kategori kuat.

3. Hubungan antara Kepemimpinan Kepala Sekolah (X1) terhadap Profesionalisme Guru (Y) adalah 0,757. Nilai ini masuk kedalam kategori kuat.

4. Hubungan antara Budaya Sekolah (X2) terhadap Profesionalisme Guru (Y) adalah 0, 364. Nilai ini masuk kedalam kategori kuat.

5. Hubungan antara Motivasi Kerja Guru (X3) terhadap Profesionalisme Guru (Y) adalah 0, 364. Nilai ini masuk kedalam kategori kuat.

6. Hubungan antara Kepemimpinan Kepala Sekolah (X1) dan Motivasi Kerja Guru (X3) terhadap Profesionalisme Guru (Y) adalah 0,790. Nilai ini masuk kedalam kategori sangat kuat. Kemudian untuk mengetahui seberapa besar sumbangan variabel eksogen terhadap endogen dari tabel di atas koefisien Determinan diperoleh 62,5\%.

7. Hubungan antara Hubungan antara Budaya Sekolah (X2) dan Motivasi Kerja Guru (X3) terhadap Profesionalisme Guru (Y) adalah 0,714. Nilai ini masuk kedalam kategori kuat. Kemudian untuk mengetahui seberapa besar sumbangan variabel eksogen terhadap endogen dari tabel di atas koefisien Determinan diperoleh 51\%.

Sehingga diperoleh diagram jalur sebagai berikut:

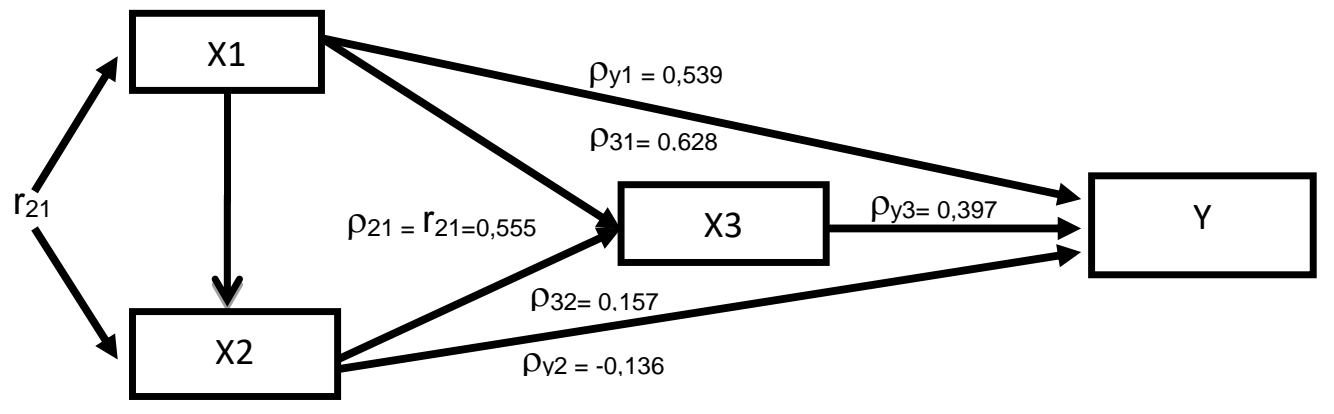

Gambar 1. Diagram Jalur Substruktural Kedua

Dari hasil pengujian koefisien jalur diperoleh keterangan bahwa koefisien jalur dari X1 ke X3, X1 ke $Y, X 3$ ke $Y$ ketiganya secara statistik 
adalah bermakna (thitung $>$ tabel dan $p$-value $<0,05$ ). Sedangkan koefisien jalur X2 ke X3, dan X2 ke Y adalah tidak bermakna (thitung $<$ tabel dan $p$ value $>0,05)$.

\section{Pembahasan}

\section{Hubungan Kepemimpinan Kepala Sekolah dengan Motivasi Kerja Guru}

Hasil penelitian menunjukkan bahwa terdapat pengaruh langsung secara signifikan antara Kepemimpinan Kepala Sekolah dengan Motivasi Kerja Guru Penjas tingkat SMK di Kabupaten Serdang Bedagai. Hasil ini sejalan dengan pendapat dari Leitwood dan Jantzi dalam Emmanouil, Osia, dan loanna (2014:34) yang menyatakan bahwa Kepala Sekolah harus berperan sebagai motivator yang baik agar dapat menumbuhkan motivasi kerja guru demi tercapainya tujuan pendidikan di sekolah. Sama halnya dengan yang diungkapkan oleh Manik \& Bustomi (2011) yang menyatakan bahwa "kepemimpinan merupakan suatu pola perilaku para pemimpin dalam mengarahkan dan mengendalikan para bawahan untuk mengikuti kehendaknya dalam mencapai sauatu tujuan dan sasaran yang telah ditetapkan".

\section{Hubungan Budaya Sekolah dengan Motivasi Kerja Guru}

Hasil penelitian menunjukkan bahwa tidak terdapat pengaruh langsung secara signifikan antara Budaya Sekolah dengan Motivasi Kerja Guru Penjas tingkat SMK di Kabupaten Serdang Bedagai. Hal ini sesuai dengan pernyataan Maryamah (2016) bahwa "Dalam masyarakat, kebudayaan itu disatu pihak dipengaruhi oleh anggota masyarakat, tetapi dilain pihak anggota masyarakat dipengaruhi oleh kebudayaan.", Hal ini sejalan dengan pernyataan Selo Sumarjan dalam Maryamah (2016) bahwa "tidak setiap budaya dapat mempengaruhi baik buruknya kinerja seseorang. Namun teori lain menyatakan bahwa Budaya Sekolah berpengaruh terhadap tingkah laku dan kebiasaan dari setiap individu. Seperti yang di ungkapkan oleh Daryanto (2015) bahwa budaya sekolah merupakan komponen yang sangat penting untuk memajukan sekolah 
yaitu dengan memastikan budaya sekolah yang positif dan memberi perhatian kepada ibu, bapak guru dan siswa lainnya.

\section{Hubungan Kepemimpinan Kepala Sekolah dengan Profesionalisme Guru}

Hasil penelitian menunjukkan bahwa terdapat pengaruh langsung yang signifikan antara Kepemimpinan kepala Sekolah dengan Profesionalisme Guru Pendidikan Jasmani tingkat SMK di Kabupaten Serdang Bedagai. Hal ini sesuai dengan teori Azhar (2014) bahwa "tugas kepala sekolah adalah untuk dapat menciptakan guru profesional agar bisa bekerja sesuai dengan pengarahan yang diberikan". Keith dalam Guterres \& Supartha (2016) mengartikan bahwa "kepemimpinan adalah kemampuan seseorang untuk mengetahui orang lain dalam mencapai tujuan dan antusias.

\section{Hubungan Budaya Sekolah dengan Profesionalisme Guru}

Hasil penelitian menunjukkan bahwa tidak terdapat pengaruh langsung yang signifikan antara Budaya Sekolah dengan Profesionalisme Guru Pendidikan Jasmani tingkat SMK di Kabupaten Serdang Bedagai. Hal ini sejalan dengan pendapat dari Neprializa (2015) yang menyatakan bahwa "budaya merupakan produk lembaga yang berakar dari sikap mental, komitmen, dedikasi dan loyalitas setiap personil lembaga". Yang artinya bahwa semua anggota organisasi berperan untuk membentuk budaya. Baik buruknya suatu budaya suatu organisasi ditentukan oleh orang-orang yang ada didalam lembaga tersebut. Schoen dalam Widodo (2017) menyatakan bahwa "budaya sekolah bergantung kepada sikap dan tingkah laku setiap warga sekolah". Artinya jika dikaitkan dengan penelitian bahwa budaya tidak mempengaruhi profesionalisme guru, namun tingkat profesionalisme guru dapat menciptakan budaya sekolah yang baik dan sehat demi lancarnya pembelajaran di sekolah.

\section{Hubungan Motivasi Kerja Guru dengan Profesionalisme Guru}

Hasil penelitian menunjukkan bahwa terdapat pengaruh langsung yang signifikan antara Motivasi Kerja Guru dengan Profesionalisme Guru Pendidikan Jasmani tingkat SMK di Kabupaten Serdang Bedagai. Hal ini 
sejalan dengan yang diungkapkan Safwan, Nadirsyah, \& Abdullah (2014) bahwa "motivasi merupakan keadaan pribadi seseorang yang mendorong keinginan individu untuk melakukan kegiatan-kegiatan tertentu guna mencapai suatu tujuan". Dari penjelasan diatas dapat disimpulkan bahwa motivasai merupakan suatu keinginan atau doringan seseorang untuk melakukan suatu kegiatan demi tujuan yang diinginkan.

\section{Hubungan Kepemimpinan Kepala Sekolah dan Motivasi Kerja Guru dengan Profesionalisme Guru}

Hasil penelitian menunjukkan bahwa terdapat pengaruh yang signifikan antara kepemimpinan kepala sekolah dan motivasi kerja guru dengan profesionalisme guru penjas tingkat SMK di Kabupaten Serdang Bedagai. Hal ini sejalan dengan pendapat Daryanto (2015) yang menyatakan bahwa "kepemimpinan kepala sekolah berperan dalam kegiatan pembinaan personil guru, perlindungan sekolah terhadap tekanan eksternal yang kurang mendukung, pemantauan prestasi sekolah, penyedian waktu dan energi untuk perbaikan sekolah, pemberian dukungan kepada guru, dan pencarian sumber daya ektra untuk sekolahnya". Kepala sekolah harus mengetahui motif dan motivasi yang diinginkan oleh guru. Kepemimpinan kepala sekolah yang efektif adakah kunci di dalam memotivasi guru untuk meningkatkan profesionalismenya, sementara guru yang termotivasi akan muncul kemauan untuk melakukan tugas pokoknya dengan penuh semangat dan tanggung jawab (Rini, 2018; Setiyati, 2014).

\section{Hubungan Budaya Sekolah dan Motivasi Kerja Guru terhadap Profesionalisme Guru}

Hasil penelitian menunjukkan bahwa tidak terdapat pengaruh langsung antara Budaya Sekolah dan Motivasi Kerja Guru terhadap Profesionalisme Guru Penjas tingkat SMK di Kabupaten Serdang Bedagai. Sejalan dengan hasil temuan ini, Abast (2015:89) menjelaskan bahwa "budaya sekolah berpengaruh penting untuk kemajuan sekolah dengan dibantu faktor-faktor pendukung lainnya". Dengan demikian 
budaya sekolah dapat menentukan tinggi rendahnya profesionalisme guru melalui faktor lain yaitu motivasi kerja guru.

\section{KESIMPULAN DAN SARAN}

\section{Kesimpulan}

Hasil temuan penelitian ini adalah kepemimpinan kepala sekolah yang baik, budaya sekolah yang sehat, dan motivasi kerja guru yang tinggi merupakan faktor penentu profesionalisme guru. Untuk meningkatkan motivasi kerja guru maka Kepala Sekolah harus berperan sebagai motivator yang baik demi menumbuhkan rasa percaya diri guru dalam melaksanakan tugasnya. Dengan demikian guru sebagai tenanga pendidik harus berupanya mengembangkan kompetensi yang dimiliki demi tercapainya tujuan pendidikan.

\section{Saran}

Guru diharapkan dapat meningkatkan empat kompetensi yang harus kuasai oleh seorang guru, sehingga dengan dikuasainya keempat kompetensi tersebut dapat meningkatkan profesionalisme seorang guru Pendidikan Jasmani. Hasil temuan ini juga menjadi masukan yang konstruktif bagi setiap kepala sekolah supaya dalam memimpin harus mampu mengelola dan menciptakan lingkugan belajar yang kondusif agar terciptanya proses belajar menngajar yang diharapkan serta dapat menciptakan Budaya Sekolah yang sehat untuk dapat dilaksanakan seterusnya dimasa yang akan datang.

\section{DAFTAR PUSTAKA}

Abast, R. M. (2011). Hubungan Motivasi dan Iklim Kerja dengan Produktivitas Guru SMK di Kota Manado. Jurnal Pendidikan Teknologi Dan Kejuruan, 2(2), 71-82.

Astuti, S. (2015). Hubungan Antara Sertifikasi dan Motivasi Kerja dengan Kinerja Guru SD Negeri Kecamatan Jekan Raya Kota Palangka Raya. Jurnal Pendidikan, 3(2), 112-119.

Azhar, A. (2014). Pengaruh Kepemimpinan Kepala Sekolah dan Profesionalisme Guru terhadap Kinerja Guru Sekolah dasar Negeri. In Seminar Nasional Evaluasi Pendidikan.

Bank Dunia. (2011). Mentransformasi Tenaga Pendidikan Indonesia 
((Volume II). Jakarta: Bank Dunia.

Daryanto, D. (2015). Pengelolaan Budaya dan Iklim Sekolah. Yogyakarta: Gava Media.

Demirkasimoǧlu, N. (2010). Defining "teacher professionalism" from different perspectives. Procedia - Social and Behavioral Sciences, 9, 2047-2051. https://doi.org/10.1016/j.sbspro.2010.12.444

Emmanouil, K., Osia, A., \& Paraskevi, L. (2014). The Impact of Leadership Teachers' Effectiveness. Journal International of Human and Social Science, 4(1), 34-39.

Guterres, A. L., \& Supartha, G. W. (2016). Pengaruh Gaya Kepemimpinan dan Motivasi Kerja Terhadap Kinerja Guru. Jurnal Ekonomi Dan Bisnis Universitas Udayana, 5(3), 429-454.

Hanief, Y. N., \& Sugito, S. (2015). Membentuk Gerak Dasar Pada Siswa Sekolah Dasar Melalui Permainan Tradisional. Jurnal SPORTIF: Jurnal Penelitian Pembelajaran, 1(1), 100-113. https://doi.org/https://doi.org/10.29407/js_unpgri.v1i1.575

Harmono, S. (2017). Pengaruh Model Pembelajaran Quantum Dan Gaya Belajar Terhadap Pemahaman Konseptual Dan Ketrampilan Gerak Pada Mata Pelajaran Pendidikan Jasmani Olahraga Dan Kesehatan Siswa SMA Kota Kediri. Jurnal SPORTIF: Jurnal Penelitian Pembelajaran, 3(1), 103-114. https://doi.org/10.29407/js_unpgri.v3i1.745

Hoesein, E. M. (2015). Using Mobile Technology and Online Support to Improve Language Teacher Professionalism. Procedia - Social and Behavioral Sciences, 192, 491-497. https://doi.org/10.1016/j.sbspro.2015.06.076

Husain, M. Z., Hasan, A., Wahab, N. B. A., \& Jantan, J. (2015). Determining Teaching Effectiveness for Physical Education Teacher. Procedia - Social and Behavioral Sciences, 172, 733-740. https://doi.org/10.1016/j.sbspro.2015.01.426

Jakaria, Y. (2014). Analisis Kelayakan dan Kesesuaian antara Latar Belakang Pendidikan Guru Sekolah Dasar dengan Mata Pelajaran yang Diampu. Jurnal Pendidikan Dan Kebudayaan, 20(4), 499-514.

Mahdiansyah, M. (2010). Perilaku professional guru kejuruan hasil penelitian di SMK Negeri DKI Jakarta. Jurnal Penelitian Kebijakan Pendidikan, 9(1), 1-23.

Manik, E., \& Bustomi, K. (2011). Pengaruh Kepemimpinan Kepala Sekolah, Budaya Organisasi Dan Motivasi Kerja Terhadap Kinerja Guru Pada SMP Negeri 3 Rancaekek. Jurnal Ekonomi, Bisnis \& Entrepreneurship, 5(2), 97-107. Retrieved from 
http://jurnal.stiepas.ac.id/index.php/jebe/article/view/12

Maryamah, E. (2016). Pengembangan Budaya Sekolah. Jurnal Manajemen Pendidikan Islam, 2(1), 86-96.

Mizzel, H. (2010). Why Professional Development Matters. Oxford: Learning Forward.

Muhson, A. (2012). Meningkatkan Profesionalisme Guru: Sebuah Harapan. Jurnal Ekonomi Dan Pendidikan, 1(2), 90-98. https://doi.org/10.21831/jep.v1i2.665

Neprializa, N. (2015). Manajemen budaya sekolah. Manajer Pendidikan, 9(3), 419-429. Retrieved from https://ejournal.unib.ac.id/index.php/manajerpendidikan/article/view File/1139/947

Rini, R. (2018). Pengaruh Kepemimpinan Kepala Sekolah, Budaya Sekolah dan Iklim Sekolah Terhadap Kompetensi Kepribadian Guru SMPN di Baradatu Way Kanan. Universitas lampung.

Safwan, S., Nadirsyah, N., \& Abdullah, S. (2014). Pengaruh Kompetensi dan Motivasi Terhadap Kinerja Pengelola Keuangan Daerah pada Pemerintah Daerah Kabupaten Pidie Jaya. Jurnal Akuntansi, 3(1), 133-139.

Samto, S. (2014). Analisis Kebutuhan dan Kompetensi Guru. Jakarta: Pusat Pengembangan Profesi Pendidik, Badan Pengembangan Sumber Daya Manusia Pendidikan dan Penjaminan Mutu Pendidikan.

Saqipi, B., Asunta, T., \& Korpinen, E. (2014). Understanding the Context of Teacher Professionalism in Education Systems Undergoing Transition - Kosovo Case. Procedia - Social and Behavioral Sciences, 112(Iceepsy 2013), 635-646. https://doi.org/10.1016/j.sbspro.2014.01.1211

Setiyati, S. (2014). Pengaruh Kepemimpinan Kepala Sekolah, Motivasi Kerja, dan Budaya Sekolah Terhadap Kinerja Guru. Jurnal Pendidikan Teknologi Dan Kejuruan, 22(2), 200-206. https://doi.org/10.21831/JPTK.V22I2.8931

Suharjo, S. (2015). Pentingnya Pendidikan Jasmani Bagi Setiap Peserta Didik. Jurnal Pedagogik Keolahragaan, 1(1), 1-13.

Supriadi, O. (2009). Pengembangan Profesionalisme Guru Sekolah dasar. Jurnal Tabularasa, 6(1), 27-38.

Syakir, M. J., \& Pardjono, P. (2015). Pengaruh Kepemimpinan Kepala Sekolah, Motivasi Kerja, dan Budaya Organisasi Terhadap Kompetensi Guru SMA. Jurnal Akuntabilitas Manajemen 
Albadi Sinulingga, Suprayitno, dan Dian Pertiwi

Profesionalisme guru pendidikan jasmani: dari kepemimpinan kepala sekolah, budaya sekolah hingga motivasi kerja guru

Pendidikan, 3(2), 226-240. https://doi.org/10.21831/amp.v3i2.6339

Widodo, H. (2017). Manajemen Perubahan Budaya Sekolah. MANAGERIA: Jurnal Manajemen Pendidikan Islam, 2(2), 287-306. https://doi.org/10.14421/manageria.2017.22-05

Zubaidah, S. (2015). Pengaruh Budaya Sekolah dan Motivasi Kerja Guru Terhadap Mutu Pendidikan di SMK N 1 Pabelan. In Prosiding Seminar Nasional. 